\title{
Correlation between Carotid and Brachial Artery Velocity Time Integral and Their Comparison to Pulse Pressure Variation and Stroke Volume Variation for Assessing Fluid Responsiveness
}

\author{
Malini Joshi ${ }^{1} \oplus$, Praveen Dhakane ${ }^{2} \odot$, Shilpushp J Bhosale ${ }^{3} \odot$, Rutuja Phulambrikar ${ }^{4} \odot$, Atul P Kulkarni ${ }^{5} \odot$
}

\begin{abstract}
Background: Fluid boluses are used in hemodynamically unstable patients with presumed hypovolemia, to improve tissue perfusion, in the perioperative period. Now less invasive methods, such as pulse pressure variation (PPV) and stroke volume variation (SVV) are increasingly being used. We investigated correlation between carotid and brachial artery velocity time integral (VTI) and compared both with PPV and SVV. Methods: We recruited 27 patients undergoing supra-major abdominal surgeries. When indicated (hypotension or increased lactate), a fluid bolus was given after measuring carotid and brachial artery VTI, PPV, and SVV. The change in SV was noted and patients were categorized as responders if the SV increased by $>15 \%$. We performed Bland Altman Agreement and calculated best sensitivity and specificity for the parameters. Results: Patients were found to be fluid responders on 29 instances. The correlation between PPV, SVV, carotid and brachial artery VTI was poor and the limits of agreement between them were wide. The Area under Curve (AUC) for PPV was 0.69, for SVV was 0.63, while those of Carotid and Brachial artery VTI (TAP and flow) were $(0.53$ and 0.54 for carotid) and ( 0.51 and 0.56 for brachial) respectively.

Conclusion: We found poor agreement and weak correlation between both VTi (TAP and flow) measured at carotid and brachial arteries, suggesting that the readings at brachial vessel cannot be used interchangeably with those at carotid artery. The PPV and SVV were better than these parameters for predicting fluid responsiveness; however, their predictive ability (AUROC), sensitivity and specificity were much lower than previously reported. Further studies in this area are therefore required (CTRI Reg No: CTRI/2017/08/009243).

Keywords: Fluid responders, Fluid responsiveness, Hypoperfusion, Hypovolemia, Pulse pressure variation, Stroke volume variation, Velocity time integral.

Indian Journal of Critical Care Medicine (2022): 10.5005/jp-journals-10071-24115
\end{abstract}

\section{INTRODUCTION}

Fluid boluses are used in hemodynamically unstable patients with presumed hypovolemia to improve tissue perfusion. When cardiac index $(\mathrm{Cl})$ increases after fluid bolus patients are called responders; this occurs when they are on the steep portion of the Frank Starling curve. However, bedside assessment of fluid responsiveness (FR) remains challenging. ${ }^{1}$

Compared to the static measures [pulmonary artery occlusion pressure (PAOP) and central venous pressure (CVP)], dynamic measures such as pulse pressure variation (PPV) and systolic pressure variation (SPV) are better predictors of FR. ${ }^{2-5}$ PPV and SVV measurements need arterial cannulation and these may not predict fluid responsiveness under all conditions. ${ }^{1,6}$ Arterial cannulation itself can cause infections and embolic complications. ${ }^{7}$

Availability of portable ultrasound machines has made noninvasive measurement of hemodynamic parameters, such as aortic blood flow (ABF) or aortic velocity time integral (VTi), possible. ${ }^{8}$ Recently, measurement of carotid and brachial VTi has been shown to be useful for FR prediction. ${ }^{9-11}$ The correlation and degree of agreement between carotid and brachial artery VTi has not been studied before. We therefore evaluated the correlation and agreement between VTI (TAP, time average peak and flow corrected to vessel size) at carotid and brachial arteries
${ }^{1}$ Department of Anaesthesiology, Critical Care and Pain, Tata Memorial Hospital, Homi Bhabha National Institute, Mumbai, Maharashtra, India ${ }^{2}$ Department of Anaesthesia, Critical Care and Pain, Tata Memorial Hospital, Homi Bhabha National Institute, Mumbai, Maharashtra, India ${ }^{3}$ Department of Critical Care Medicine, Tata Memorial Centre, Homi Bhabha National Institute, Mumbai, Maharashtra, India

${ }^{4}$ Department of Community Medicine, Tata Memorial Centre, Homi Bhabha National Institute, Mumbai, Maharashtra, India

${ }^{5}$ Division of Critical Care Medicine, Department of Anaesthesia, Critical Care and Pain, Tata Memorial Hospital, Homi Bhabha National Institute, Mumbai, Maharashtra, India

Corresponding Author: Atul P Kulkarni, Division of Critical Care Medicine, Department of Anaesthesia, Critical Care and Pain, Tata Memorial Hospital, Homi Bhabha National Institute, Mumbai, Maharashtra, India, Phone: +91 9869077526, e-mail: kaivalyaak@ yahoo.co.in

How to cite this article: Joshi M, Dhakane P, Bhosale SJ, Phulambrikar R, Kulkarni AP. Correlation between Carotid and Brachial Artery Velocity Time Integral and Their Comparison to Pulse Pressure Variation and Stroke Volume Variation for Assessing Fluid Responsiveness. Indian J Crit Care Med 2022;26(2):179-184.

Source of support: Nil

Conflict of interest: None

(O) The Author(s). 2022 Open Access This article is distributed under the terms of the Creative Commons Attribution 4.0 International License (https://creativecommons. org/licenses/by-nc/4.0/), which permits unrestricted use, distribution, and non-commercial reproduction in any medium, provided you give appropriate credit to the original author(s) and the source, provide a link to the Creative Commons license, and indicate if changes were made. The Creative Commons Public Domain Dedication waiver (http://creativecommons.org/publicdomain/zero/1.0/) applies to the data made available in this article, unless otherwise stated. 


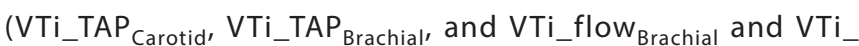
flow $_{\text {Carotid }}$. We also compared the ability of these parameters to PPV and SVV to predict FR in adults.

\section{Materials and Methods}

We conducted this study after Institutional Ethics Committee (IEC) approval and informed consent. We included adults ( $>18$ years) undergoing elective, supra-major abdominal oncosurgeries under GA. Patients with known peripheral vascular disease, carotid artery disease, history of heart failure, valvular heart disease, and arrhythmias were excluded. Anesthesia technique was standardized. Along with routine monitoring, all patients had their radial artery cannulated, for invasive arterial pressure monitoring. Cardiac output was monitored using FloTrac $^{\mathrm{TM}}$ device with EV1000 ${ }^{\mathrm{TM}}$ clinical platform (Edwards Lifesciences, Irvine California, USA). The patient's lungs were ventilated with tidal volume $6 \mathrm{~mL} / \mathrm{kg}$ predicted body weight, with respiratory rate $12-14$ minute, I:E ratio $1: 2$, and PEEP $5 \mathrm{~cm} \mathrm{H}_{2} \mathrm{O}$.

The demographic data, details of surgery, and use of vasopressors (and dose, if used) were recorded. Indications for the fluid challenge were noted. The respiratory (peak and plateau pressures) and hemodynamic parameters (HR, SBP, MAP, Cl, SV, PPV, SVV, VTi_TAP Carotid, $_{\text {VTi_TAP }}$ Brachial, VTi_flow Carotid, $_{\text {, }}$ and VTi_flow Brachial $_{1}$ ) were recorded at baseline, before and after fluid bolus. The tidal volume was transiently increased to $8 \mathrm{~mL} / \mathrm{kg}$ PBW at the time of observations. Fluid responsiveness was defined as an increase in the SV by $15 \%$ in response to fluid administration.

When clinically indicated (hypotension, and/or need for vasopressors, oliguria, lactate levels $>2 \mathrm{mmol} / \mathrm{L}$ ), a fluid bolus of $7 \mathrm{~mL} / \mathrm{kg}$ Ringers Lactate was given over 30 minutes.

PPV was measured using Philips IntelliVue MP70 monitor. SVV, $\mathrm{SV}$, and $\mathrm{Cl}$ were recorded using the $\mathrm{EV} 1000^{\mathrm{TM}}$ clinical platform. A maximum of three sets for all parameters were recorded in every patient, with a gap of at least 2 hours between the two readings.

The Doppler imaging for carotid and brachial artery measurements (VTI TAP i.e., time average peak and flow measured from vessel size by software in machine) were done by a portable ultrasound device, SonoSite Titan HCU (SonoSite; M-TURBO ${ }^{\text {TM }}$, FUJIFILM Sonosite India Pvt. Ltd). A 7-13 MHz broadband linear array transducer was used to obtain carotid and brachial arterial Doppler measurements. The Doppler measurements $\left(\mathrm{VTi}_{-} \mathrm{TAP}_{\text {Carotid }}\right.$ and $V_{T i} T_{A P} P_{\text {Brachial }}$ and VTi_flow Carotid $_{\text {and }}$ VTi_flow Brachial $_{\text {) }}$ ) were carried out by a single investigator trained in critical care ultrasound. The brachial artery imaging was performed in the antecubital fossa, on the side without radial artery cannulation. The blood flow velocity was recorded at the midstream of the vessel lumen over 10 seconds with the sample volume adjusted at the center of the artery. The carotid artery velocity waveform was recorded after obtaining a longitudinal view of the common carotid artery, within $2 \mathrm{~cm}$ of the bifurcation. The sample volume was positioned the center of the vessel, with Doppler angulation at approx $20^{\circ}$ (not more than $60^{\circ}$ ). All image angles were corrected up to $15^{\circ}$ for the best signal and stored for immediate review following each measurement. An in-built software in the machine computed the VTi_TAP and VTi_flow. The clinician obtaining ultrasound images was blinded to the results of the PPV and SVV, while the clinician recording the PPV and SVV values was blinded to the Doppler results.

Patients were divided into two groups, responders and nonresponders, based on increase in stroke volume (SV) $\geq 15 \%$, and we tried to identify the predictors of FR.

\section{Sample Size}

This study was meant to be a proof of concept study; we chose a convenience sample size of 50 instances requiring fluid boluses. The fluid boluses were given in 27 patients, when clinically indicated. In nine patients, fluid challenge was required only once, in 13 patients twice, and thrice in five patients.

\section{Statistical Analysis}

Data was analyzed using SPSS Statistics version 21 software. Quantitative variables were described using mean \pm SD where data were normally distributed and using median (IQR), where it was skewed. Paired $t$ test was used to compare the change in hemodynamic parameters. Student's $t$-test or Mann-Whitney $U$ test was used to compare the hemodynamic parameters between responders and nonresponders.

The relation between quantitative variables VTi_TAP $_{\text {Carotid }}$ VTi_TAP Brachial $_{\text {) }}$ was assessed using Pearson and Spearman correlation coefficients according to normality test. Bland-Altman plots were used to describe agreement between VTi_TAP Carotid $_{\text {. }}$

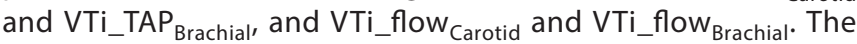
receiver operating characteristic (ROC) curves were generated to identify predictors of fluid response and based on highest sensitivity and specificity, cut-offs for PPV, SVV, VTi_TAP Carotid $_{\text {. }}$ and VTi_TAP Brachial, $_{\text {VTi_flow }}$ Carotid and VTi_flow Brachial $_{\text {Were }}$ determined. All analyses were two-sided, and significance was set at a $p$-value of 0.05 .

\section{Results}

We included 50 sets of measurements from 27 adults undergoing elective supra-major abdominal surgeries. The mean age of patients was $53( \pm 20)$ years and most patients (24) had gastrointestinal malignancies (Table 1). The commonest indications for fluid bolus were hypotension and need for vasopressors (Table 2). Based on the response to fluid bolus, the patients were divided into responders and nonresponders. Table 3 shows the baseline and subsequent (after increasing tidal volume) peak and plateau pressures. Table 4 summarizes the hemodynamic parameters before and after fluid boluses. On 58\% occasions, patients were fluid-responsive (Table 4).

We found weak correlation between VTi_TAP Carotid $_{\text {and }}$ an VTi_TAP Brachial $\left(r^{2}=0.143\right)$ and VTi_flow Carotid $_{\text {and }}$ VTi_flow Brachial $\left(r^{2}=0.0004\right)$ (Figs 1 and 2). The bias and limits of agreement between the readings taken at carotid and brachial arteries for VTi_TAP and VTi_flow were also wide (Figs 3 and 4). The predictive abilities of PPV and SVV were similar to each other, but low [PPV Receiver Operating Characteristics Curve (AUROC) 0.628 and SVV (AUROC 0.631)]. The AUROC for both VTi_TAP and VTi_flow at carotid and brachial vessels was close to 0.5 , suggesting predictive

Table 1: Patients characteristics and primary diagnosis

\begin{tabular}{lc}
\hline Characteristics & Data $($ mean \pm SD) \\
\hline Age (years) & $53 \pm 20$ \\
Height $(\mathrm{cm})$ & $162 \pm 17$ \\
Weight $(\mathrm{kg})$ & $59 \pm 14$ \\
BMI & $22.9 \pm 4.8$ \\
Females & 13 \\
Males & 14 \\
\hline Primary diagnosis & No. of patients \\
\hline Gastrointestinal malignancies & 24 \\
Genitourinary malignancies & 03 \\
\hline
\end{tabular}


Table 2: Surgical procedures, blood loss, fluid and blood transfusions, and indications for fluid bolus

\begin{tabular}{|c|c|c|c|}
\hline \multicolumn{3}{|c|}{ Surgical procedures } & $n$ \\
\hline \multicolumn{3}{|c|}{ Anterior resection } & 1 \\
\hline \multicolumn{3}{|c|}{$\begin{array}{l}\text { Cytoreductive surgery } \\
\text { gynae/genitourinary }\end{array}$} & 2 \\
\hline \multicolumn{3}{|c|}{$\begin{array}{l}\text { Colorectal cytoreductive surgery } \\
\text { with hyperthermic intraperitoneal } \\
\text { chemotherapy (CRS + HIPEC) }\end{array}$} & 8 \\
\hline \multicolumn{3}{|c|}{ Duodenojejunal flexure resection } & 1 \\
\hline \multicolumn{3}{|c|}{$\begin{array}{l}\text { Colorectal cytoreductive surgery } \\
\text { without hyperthermic } \\
\text { intraperitoneal chemotherapy } \\
\text { (HIPEC) }\end{array}$} & 12 \\
\hline \multicolumn{3}{|c|}{$\begin{array}{l}\text { Pylorus preserving pancreatico- } \\
\text { duodenectomy (PPPD) }\end{array}$} & 1 \\
\hline \multicolumn{3}{|c|}{$\begin{array}{l}\text { Radical cystectomy with ileal } \\
\text { Conduit }\end{array}$} & 1 \\
\hline \multicolumn{3}{|c|}{$\begin{array}{l}\text { Retroperitoneal lymph node } \\
\text { dissection and repair of inferior } \\
\text { vena cava (RPLND + IVC repair) }\end{array}$} & 1 \\
\hline \multicolumn{4}{|c|}{ Blood loss, fluids and blood and blood products transfused } \\
\hline \multicolumn{2}{|c|}{ Blood loss, $\mathrm{mL}$} & 278 & $3.33 \pm 2144.27$ \\
\hline \multicolumn{2}{|c|}{ Crystalloids, mL } & 486 & $2.96 \pm 2944.77$ \\
\hline \multicolumn{2}{|c|}{ Colloids, mL } & 128 & $6.11 \pm 1119.8$ \\
\hline \multicolumn{2}{|c|}{$\begin{array}{l}\text { PRBCs transfused, no of units } \\
\text { (10 patients) }\end{array}$} & & $2.18 \pm 2.39$ \\
\hline \multicolumn{2}{|c|}{$\begin{array}{l}\text { FFPs transfused, no of units } \\
\text { (8 patients) }\end{array}$} & & $2.18 \pm 2.39$ \\
\hline \multicolumn{2}{|c|}{ Indications for fluid bolus @ } & & o of patients \\
\hline \multicolumn{2}{|c|}{ Hypotension } & & 10 \\
\hline \multicolumn{2}{|c|}{ Lactates $>2 \mathrm{mmol} / \mathrm{L}$} & & 04 \\
\hline \multicolumn{2}{|c|}{ Need for vasopressors } & & 16 \\
\hline \multicolumn{4}{|c|}{${ }^{\circledR}$ Some patients had more than one indication for fluid bolus } \\
\hline \multicolumn{2}{|c|}{ Peak pressure } & Plate & au pressure \\
\hline $\begin{array}{l}\text { aseline } \\
5 \mathrm{~mL} / \mathrm{kg})\end{array}$ & $\begin{array}{l}\text { After increasing } \\
\text { TV }(8 \mathrm{~mL} / \mathrm{kg})\end{array}$ & $\begin{array}{l}\text { Baseline } \\
(6 \mathrm{~mL} / \mathrm{kg})\end{array}$ & $\begin{array}{c}\text { After increasing TV } \\
(8 \mathrm{~mL} / \mathrm{kg})\end{array}$ \\
\hline $9.66( \pm 4.15)$ & $19.02( \pm 3.71)$ & $15.42( \pm 3.77)$ & $15.34( \pm 3.42)$ \\
\hline
\end{tabular}

ability close to a toss of a coin, i.e., very poor (Fig. 5 and Table 5). Highest sensitivity and specificity cut-offs and NPV and PPV for SVV, PPV, VTi_TAP Carotid and VTi_TAP brachial, $_{\text {, }}$ and VTi_Flow carotid $_{\text {and }}$

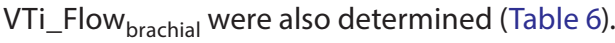

\section{Discussion}

In this prospective observational study we found weak correlation between VTi and VTi_flow (Figs 1 and 2). The bias and LOA between the readings of $\mathrm{VTi}$ and $\mathrm{VTi}$ _flow at both arteries were also wide (Figs 3 and 4).

We chose to perform this study in patients undergoing elective supra-major oncosurgeries, since during these surgeries, major blood loss and large volume shifts are common. Thus, the patients often become hemodynamically unstable (Table 2). Fast, accurate, and reliable measurement of $\mathrm{CO}$ is important for determining FR. Aortic VTi is a well-established method for assessing FR. ${ }^{8}$ However, intraoperative assessment of aortic VTi can be cumbersome in patients undergoing supra-major abdominal surgeries, where the patients are fully draped and the precordial area is difficult to access. It is also difficult to visualize and ensure correct angle of the cardiac ultrasound probe under the drape. Carotid artery Doppler imaging has been shown to be a substitute for the aortic VTI. ${ }^{9}$ However, it also presents difficulty in access, due to drapes and if central venous cannulation has been performed. Carotid and brachial Doppler imaging are easier compared to transthoracic echocardiography, which requires extensive training and is operator-dependent. Monge García et al. showed that measurement of VTi at brachial artery might be a good alternative to aortic $\mathrm{VTi}^{10}{ }^{10}$ There are no studies evaluating correlation between carotid and brachial artery parameters.

In our study, predictive value of VTi_TAP and VTi_flow at carotid and brachial arteries for FR was poor (Table 7), a finding contrary to previous studies. The AUROC in the study by Monge García et al. was 0.88 , and while it was 0.94 in the study by Brenan et al. ${ }^{10,11}$ In both these studies, patients were ventilated with higher tidal volumes: $9(8-10) \mathrm{mL} / \mathrm{kg} \mathrm{IBW}$ in the study by Monge Garcia et al., and $9( \pm 2) \mathrm{mL} / \mathrm{kg}$ IBW by Brennan et al. ${ }^{10,11}$

The low sensitivity and specificity of PPV and SVV to accurately predict fluid responsiveness at the usual cut-offs in our study is not surprising. This may have been due to low tidal volume (TV) ventilation, which is our protocol for all patients undergoing elective

Table 4: Hemodynamic variables among responders and nonresponders before and after fluid bolus

\begin{tabular}{|c|c|c|c|c|c|c|}
\hline \multirow[b]{2}{*}{ Variables } & \multicolumn{3}{|c|}{ Nonresponders } & \multicolumn{3}{|c|}{ Responders } \\
\hline & Before bolus & After bolus & $p$ value & Before bolus & After bolus & $p$ value \\
\hline $\mathrm{HR}$ (bpm) & $79.33(18.32)$ & $78.24(16.55)$ & 0.395 & $90.79(16.15)$ & $84.55(16.08)$ & $<0.001$ \\
\hline SBP (mm Hg) & 100.59 (19.38) & 112.59 (18.91) & $<0.001$ & $111.38(16.21)$ & $121.86(16.11)$ & $<0.001$ \\
\hline $\mathrm{DBP}(\mathrm{mm} \mathrm{Hg})$ & $60.31(10.37)$ & $63.55(10.18)$ & 0.023 & 65.05 (9.47) & $68.24(8.59)$ & 0.008 \\
\hline MAP $(\mathrm{mm} \mathrm{Hg})$ & $74.97(13.72)$ & 81.83 (12.93) & $<0.001$ & 82.71 (11.27) & 88.38 (10.69) & 0.002 \\
\hline Cardiac index & $3.39(0.94)$ & $3.91(0.86)$ & $<0.001$ & $3.15(0.72)$ & $3.48(0.77)$ & 0.002 \\
\hline PPV & $14.69(5.03)$ & $9.86(4.45)$ & $<0.001$ & $14.1(5.51)$ & $9.19(3.28)$ & $<0.001$ \\
\hline SVV & $25.91(12.46)$ & 30.34 (15.98) & 0.002 & $12.57(3.53)$ & $9(3.83)$ & $<0.001$ \\
\hline VTi_TAP Brachial & 22.59 (9.59) & $26.31(11.38)$ & $<0.001$ & $26.43(12.90)$ & 30.99 (16.68) & 0.027 \\
\hline VTi_Flow ${ }_{\text {Brachial }}$ & $180.43(64.72)$ & $220.52(89.2)$ & $<0.001$ & $204(75.80)$ & $252.48(92.30)$ & $<0.001$ \\
\hline VTi_TAP Carotid & 17.85 (16.92) & 23.74 (19.68) & 0.275 & $14.36(16.39)$ & $22.70(19.21)$ & 0.712 \\
\hline VTi_Flow ${ }_{\text {Carotid }}$ & $363.47(147.01)$ & $444.23(133.44)$ & 0.002 & $359.37(126.20)$ & 454.41 (114.09) & 0.19 \\
\hline
\end{tabular}

HR (bpm), heart rate beats/min; SBP, systolic blood pressure; DBP, diastolic blood pressure; MAP, mean arterial pressure; SV, stroke volume; PPV, pulse pressure variation; SVV, stroke volume variation; VTI_TAP, velocity time integral averaged peak (carotid or brachial); VTI_Flow, velocity time integral calibrated to vessel diameter (carotid or brachial) 


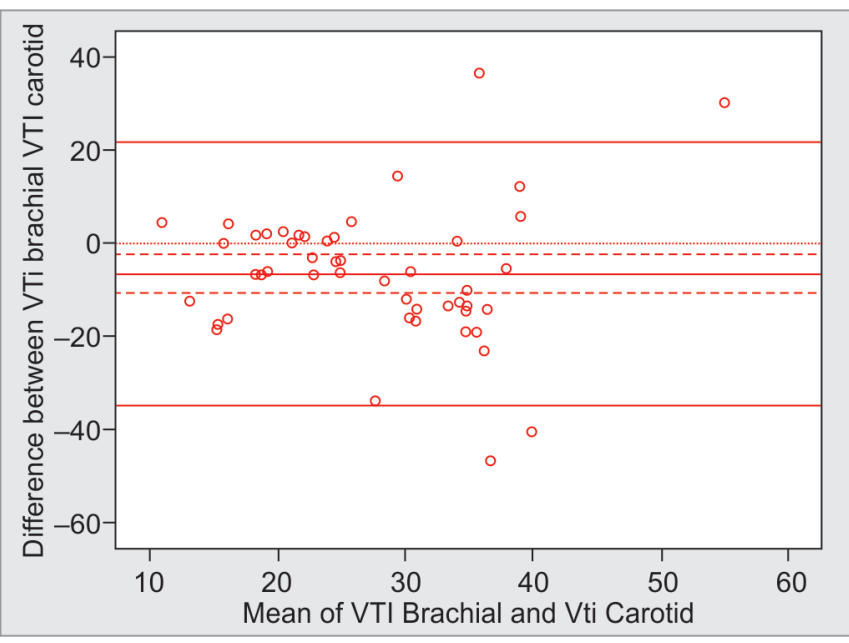

Fig. 1: Correlation between VTI_TAP at carotid and brachial arteries

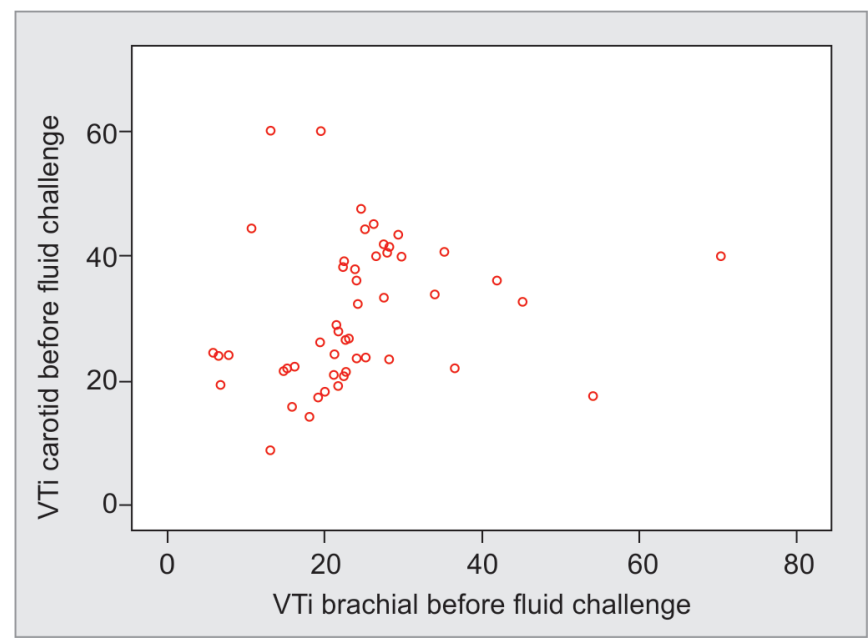

Fig. 3: Bland-Altman plot for VTI_flow at carotid and brachial arteries

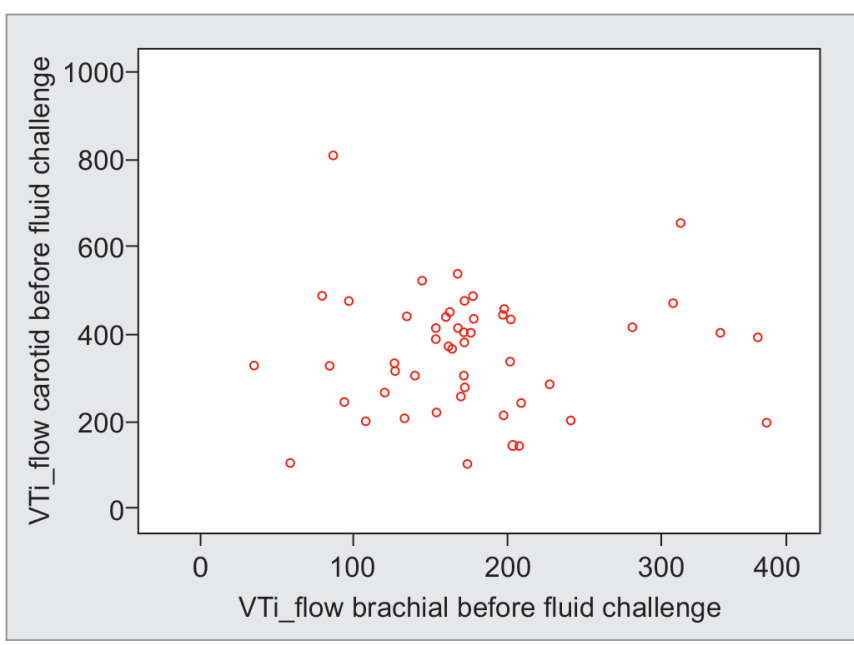

Fig. 2: Correlation between VTI_flow at carotid and brachial arteries

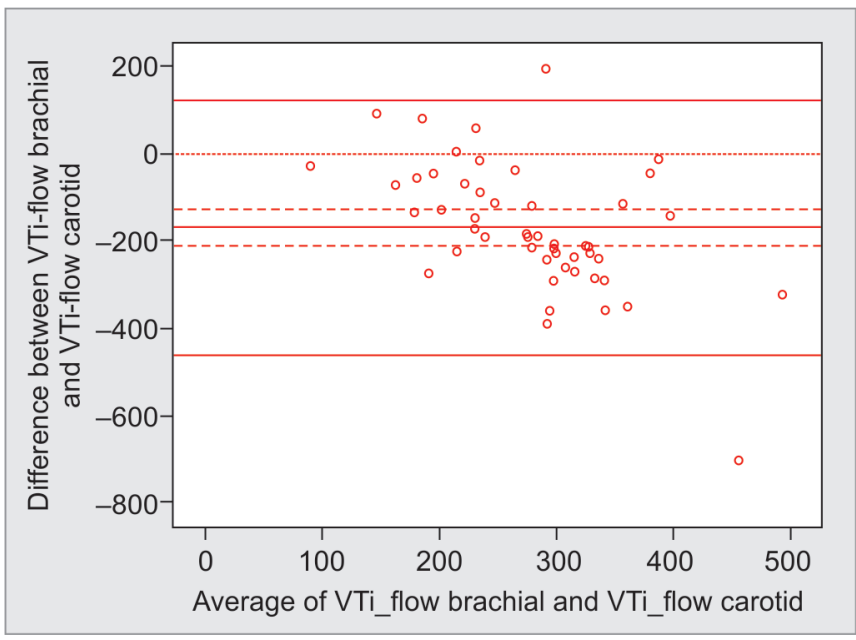

Fig. 4: Bland-Altman plot for VTI_TAP at carotid and brachial arteries

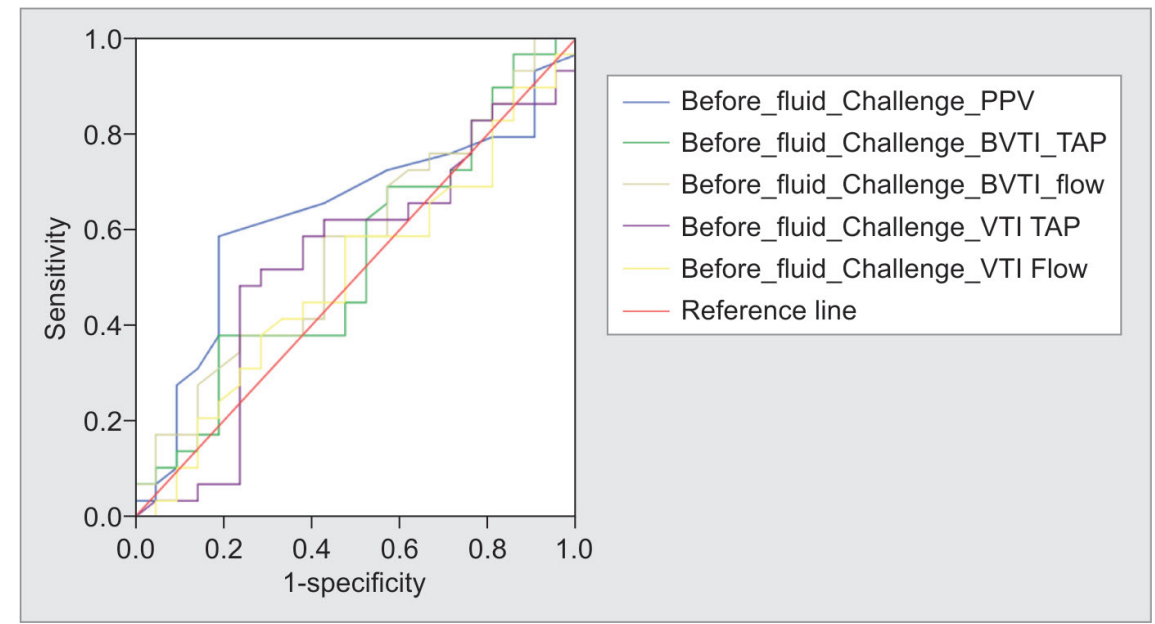

Fig. 5: ROC curves for PPV, SVV, VTI_flow, and VTi_TAP at carotid and brachial vessels 
Table 5: Predictors of patient response to fluid bolus-area under ROC curves

\begin{tabular}{lccc}
\hline Variable & AUC & $95 \% \mathrm{Cl}$ & p value \\
\hline PPV & 0.691 & $0.468-0.788$ & 0.125 \\
SVV & 0.631 & $0.474-0.787$ & 0.118 \\
VTi_TAP $_{\text {Brachial }}$ & 0.538 & $0.373-0.702$ & 0.651 \\
VTi_Flow $_{\text {Brachial }}$ & 0.567 & $0.406-0.729$ & 0.420 \\
VTi_TAP $_{\text {Carotid }}$ & 0.534 & $0.365-0.702$ & 0.687 \\
VTi_Flow $_{\text {Carotid }}$ & 0.505 & $0.341-0.668$ & 0.953 \\
\hline
\end{tabular}

HR (bpm), heart rate beats/minute; SBP, systolic blood pressure; DBP, diastolic blood pressure; MAP, mean arterial pressure; SVI, stroke volume index; PPV, pulse pressure variation; SVV, stroke volume variation; $\mathrm{VTi}_{\mathrm{A}} \mathrm{TAP}_{\text {Brachial }}$, velocity time integral averaged peakbrachial artery; VTi_TAP $_{\text {Carotidr }}$ velocity time integral averaged peak carotid artery;

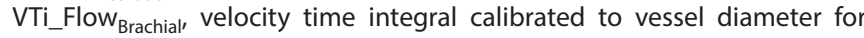

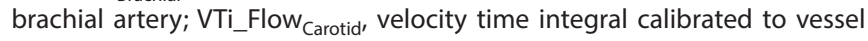
diameter for carotid artery

Table 6: Predictors of patient response to fluid bolus-area under ROC curves

\begin{tabular}{lccc}
\hline Variables & $\begin{array}{c}\text { Area under } \\
\text { ROC curve }\end{array}$ & $95 \% \mathrm{Cl}$ & p value \\
\hline PPV & 0.628 & $0.468-0.788$ & 0.125 \\
SVV & 0.631 & $0.474-0.787$ & 0.118 \\
VTi_TAP $_{\text {Brachial }}$ & 0.538 & $0.373-0.702$ & 0.651 \\
VTi_Flow $_{\text {Brachial }}$ & 0.567 & $0.406-0.729$ & 0.420 \\
VTi_TAP Carotid $_{\text {VTi_Flow }}$ & 0.534 & $0.365-0.702$ & 0.687 \\
Carotid & 0.505 & $0.341-0.668$ & 0.953 \\
\hline
\end{tabular}

PPV, pulse pressure variation; SVV, stroke volume variation; VTi_TAP $_{\text {Brachial }}$ velocity time integral averaged peak brachial artery; VTi_TAP Carotid, $_{\text {, veloci- }}$ ty time integral averaged peak carotid artery; VTi_Flow Brachial, velocity time integral calibrated to vessel diameter for brachial artery; VTi_Flow ${ }_{\text {Carotid }}$ velocity time integral calibrated to vessel diameter for carotid artery

Table 7: Sensitivity, specificity, positive, and negative predictive values for PPV, SVV, and VTI_TAP and VTI_flow at carotid and brachial vessels

\begin{tabular}{lccccc}
\hline Variable & Cut-off & Sensitivity & Specificity & PPV & NPV \\
\hline PPV & 13 & $75.9 \%$ & $28.6 \%$ & $59.5 \%$ & $46.1 \%$ \\
SVV & 10 & $89.7 \%$ & $19.1 \%$ & $60.5 \%$ & $57.1 \%$ \\
Brachial $_{\text {VTi_TAP }}$ & 10 & $62.1 \%$ & $33.3 \%$ & $56.2 \%$ & $38.9 \%$ \\
Brachial $_{\text {VTi_Flow }}$ & 10 & $70.0 \%$ & $28.6 \%$ & $57.1 \%$ & $40.0 \%$ \\
Carotid $_{\text {VTi_TAP }}$ & 10 & $72.4 \%$ & $28.6 \%$ & $58.3 \%$ & $42.9 \%$ \\
Carotid $_{\text {VTi_Flow }}$ & 10 & $82.8 \%$ & $19.0 \%$ & $58.5 \%$ & $44.4 \%$ \\
\hline
\end{tabular}

supra-major abdominal surgeries. This protocol derives from the current evidence. Futier et al. found that patients ventilated with low TV (6-8 mL/kg PBW) had lower incidence of major pulmonary and extrapulmonary postoperative complications (RR 0.40; $95 \%$ $\mathrm{Cl} 0.24-0.68 ; p=0.001)$ within seven postoperative days, as compared to those ventilated with conventional TV. (10-12 mL/ $\mathrm{kg} \mathrm{PBW}) .^{12}$ Incidence of ARF requiring NIV or invasive ventilation was lower in low TV group (5.0 vs $17 \%$, RR 0.29; $95 \% \mathrm{Cl}, 0.14-0.61$; $p=0.001)$ and hospital LOS was shorter. There was no difference in mortality. The benefits of intraoperative low TV have been confirmed in three different meta-analyses. ${ }^{13-15}$

DeBacker et al. demonstrated that PPV performed poorly (51\%) in predicting FR at TV of $8 \mathrm{~mL} / \mathrm{kg}$ IBW as compared with higher volumes (88\%). ${ }^{6}$ The performance of PPV was evaluated in a systematic review and meta-analysis of 19 studies (777 patients) ventilated with tidal volumes $<8 \mathrm{~mL} / \mathrm{kg} .{ }^{16}$ In 935 fluid challenges, 51.1\% patients were found to be fluid responsive. PPV of $10 \%$ had the fitted sensitivity of 0.65 ( $95 \% \mathrm{Cl}: 0.57-0.73$ ) to predict FR, and the specificity was 0.79 (95\% Cl:0.73-0.84). The AUROC was 0.75 . This is similar to our findings for PPV, with sensitivity of $77 \%$ and a specificity of $72 \%$ but with lower AUROC. ${ }^{16}$ The dynamic indices rely on change in intrathoracic pressure. In patients with low lung compliance due to ARDS, the changes in intrathoracic pressure induced by low TV are too small to affect the stroke volume, leading to inability of PPV or SVV to predict fluid responsiveness. We have shown in a previous study that the use of tidal volume challenge (TVC - a transient increase in TV) helps to predict FR. ${ }^{17}$ Liu et al. showed that PPV adjusted for change in pleural pressure rather than tidal volume predicted fluid responsiveness better. ${ }^{18}$ However, in our study cohort, the patients had normal lungs and there was minimal change in the peak and plateau pressure with increase in TV (Table 3). Using lower cut-offs may offer a solution; however, small errors during measurement might magnify the effects in measurements, affecting the interpretation. ${ }^{6}$

Many studies have tried to investigate if lower cut-offs improve the predictive value of PPV. While studying the effects of tidal volume and adrenergic tone on PPV and aortic VTi, Charron et al. ventilated patients with TV $6-10 \mathrm{~mL} / \mathrm{kg}$ IBW and varied the TV both ways. The PPV increased with TV both before and after volume expansion. PPV at $10 \%$ threshold had sensitivity of $89 \%$ and specificity of $83 \% .{ }^{19}$ Other studies too found improved predictive value of PPV with lower cut-offs $(6.5 \%, 10 \%) .{ }^{20,21}$ We did not find any improvement in the predictive ability of PPV with the use of lower cut-off in our cohort.

In addition to VTi_TAP, we also studied utility of VTi_flow, to see if the VTi calibrated for vessel diameter makes a difference in predicting $F R$, which has not been studied before. A small sample size could be a limitation of our study. In our study the fluid boluses were given during acute hypovolemic states and hemodynamic instability. It is possible, therefore, that the fluid bolus given $(7 \mathrm{~mL} / \mathrm{kg})$ to the patient may have been inadequate to produce the desired response in our patients or they may have responded better to bigger fluid boluses.

\section{ConCLUSiOn}

We found poor agreement and weak correlation between both VTi_TAP and VTi_flow measured at carotid and brachial arteries, suggesting that the readings at brachial vessel cannot be used interchangeably with those at carotid artery. The PPV and SVV were better than these parameters for predicting fluid responsiveness; however, their predictive ability (AUROC), sensitivity, and specificity were much lower than previously reported. Further studies in this area are therefore required.

\section{ORCID}

Malini Joshi @ https://orcid.org/0000-0001-5051-9474

Praveen Dhakane 이 https://orcid.org/0000-0002-5804-1417

Shilpushp J Bhosale (1) https://orcid.org/0000-0002-0290-0526

Rutuja Phulambrikar @ ittps://orcid.org/0000-0002-7697-3680

Atul P Kulkarni @ https://orcid.org/0000-0002-5172-7619

\section{References}

1. Marik PE, Monnet X, Teboul JL. Hemodynamic parameters to guide fluid therapy. Ann Intensive Care 2011;1(1):1. DOI: 10.1186/2110-5820-1-1.

2. Michard F, Boussat S, Chemla D, Anguel N, Mercat A, Lecarpentier Y, et al. Relation between respiratory changes in arterial pulse pressure 
and fluid responsiveness in septic patients with acute circulatory failure. Am J Respir Crit Care Med 2000;162(1):134-138. DOI: 10.1164/ ajrccm.162.1.9903035.

3. Kumar A, Anel R, Bunnell E, Habet K, Zanotti S, Marshall S, et al. Pulmonary artery occlusion pressure and central venous pressure fail to predict ventricular filling volume, cardiac performance, or the response to volume infusion in normal subjects. Crit Care Med 2004;32(3):691-699. DOI: 10.1097/01.ccm.0000114996.68110.c9.

4. Osman D, Ridel C, Ray P, Monnet X, Anguel N, Richard C, et al. Cardiac filling pressures are not appropriate to predict hemodynamic response to volume challenge. Crit Care Med 2007;35(1):64-68. DOI: 10.1097/01.CCM.0000249851.94101.4F.

5. Kim KM, Gwak MS, Choi SJ, Kim MH, Park MH, Heo BY. Pulse pressure variation and stroke volume variation to predict fluid responsiveness in patients undergoing carotid endarterectomy. Korean J Anesthesiol 2013;65(3):237-243. DOI: 10.4097/kjae.2013.65.3.237.

6. De Backer D, Heenen S, Piagnerelli M, Koch M, Vincent JL. Pulse pressure variations to predict fluid responsiveness: influence of tidal volume. Intensive Care Med 2005;31(4):517-523. DOI: 10.1007/ s00134-005-2586-4.

7. Scheer B, Perel A, Pfeiffer UJ. Clinical review: complications and risk factors of peripheral arterial catheters used for haemodynamic monitoring in anaesthesia and intensive care medicine. Crit Care 2002;6(3):199-204. DOI:10.1186/cc1489.

8. Wang J, Zhou D, Gao Y, Wu Z, Wang X, Lv C. Effect of VTI LVOT $_{\text {Variation }}$ rate on the assessment of fluid responsiveness in septic shock patients. Medicine (Baltimore) 2020;99(47):e22702. DOI: 10.1097/ MD.0000000000022702.

9. Blehar DJ, Glazier S, Gaspari RJ. Correlation of corrected flow time in the carotid artery with changes in intravascular volume status. J Crit Care 2014;29(4):486-488. DOI: 10.1016/j.jcrc.2014.03.025.

10. Monge García MI, Gil Cano A, Díaz Monrové JC. Brachial artery peak velocity variation to predict fluid responsiveness in mechanically ventilated patients. Crit Care 2009;13(5):R142. DOI: 10.1186/cc8027.

11. Brennan JM, Blair JE, Hampole C, Goonewardena S, Vasaiwala S, Shah $D$, et al. Radial artery pulse pressure variation correlates with brachial artery peak velocity variation in ventilated subjects when measured by internal medicine residents using hand-carried ultrasound devices. Chest 2007;131(5):1301-1307. DOI: 10.1378/chest.06-1768.

12. Futier E, Constantin JM, Paugam-Burtz C, Pascal J, Eurin M, Neuschwander A, et al; IMPROVE Study Group. A trial of intraoperative low-tidal-volume ventilation in abdominal surgery. N Engl J Med 2013;369(5):428-437. DOI: 10.1056/NEJMoa1301082.
13. Serpa Neto A, Hemmes SN, Barbas CS, Beiderlinden M, Biehl M, Binnekade JM, et al; PROVE Network Investigators. Protective versus conventional ventilation for surgery: a systematic review and individual patient data meta-analysis. Anesthesiology 2015;123(1): 66-78. DOI: 10.1097/ALN.0000000000000706.

14. Guay J, Ochroch EA, Kopp S. Intraoperative use of low volume ventilation to decrease postoperative mortality, mechanical ventilation, lengths of stay and lung injury in adults without acute lung injury. Cochrane Database Syst Rev 2018;7(7):CD011151. DOI: 10.1002/14651858.CD011151.pub3.

15. Deng QW, Tan WC, Zhao BC, Wen SH, Shen JT, Xu M. Intraoperative ventilation strategies to prevent postoperative pulmonary complications: a network meta-analysis of randomised controlled trials. Br J Anaesth 2020;124(3):324-335. DOI: 10.1016/j.bja.2019.10.024.

16. Alvarado Sánchez JI, Caicedo Ruiz JD, Diaztagle Fernández JJ, Ospina-Tascón GA, Cruz Martínez LE. Use of pulse pressure variation as predictor of fluid responsiveness in patients ventilated with low tidal volume: a systematic review and meta-analysis. Clin Med Insights Circ Respir Pulm Med 2020;14:1179548420901518. DOI: 10.1177/1179548420901518.

17. Myatra SN, Prabu NR, Divatia JV, Monnet X, Kulkarni AP, Teboul JL. The changes in pulse pressure variation or stroke volume variation after a "tidal volume challenge" reliably predict fluid responsiveness during low tidal volume ventilation. Crit Care Med 2017;45(3):415-421. DOI: $10.1097 / C C M .0000000000002183$.

18. Liu Y, Wei LQ, LiGQ, YuX, Li GF, Li YM. Pulse pressure variation adjusted by respiratory changes in pleural pressure, rather than by tidal volume, reliably predicts fluid responsiveness in patients with acute respiratory distress syndrome. Crit Care Med 2016;44(2):342-351. DOI: 10.1097/CCM.0000000000001371.

19. Charron C, FessenmeyerC, Cosson C, Mazoit JX, Hebert JL, Benhamou D, et al. The influence of tidal volume on the dynamic variables of fluid responsiveness in critically ill patients. Anesth Analg 2006;102(5): 1511-1517. DOI: 10.1213/01.ane.0000209015.21418.f4.

20. Freitas FG, Bafi AT, Nascente AP, Assunção M, Mazza B, Azevedo LC, et al. Predictive value of pulse pressure variation for fluid responsiveness in septic patients using lung-protective ventilation strategies. Br J Anaesth 2013;110(3):402-408. DOI: 10.1093/ bja/aes398.

21. Oliveira-Costa CD, Friedman G, Vieira SR, Fialkow L. Pulse pressure variation and prediction of fluid responsiveness in patients ventilated with low tidal volumes. Clinics (Sao Paulo) 2012;67(7):773-778. DOI: 10.6061/clinics/2012(07)12. 